\title{
Channel Structure Choice for Remanufacturing under Green Consumerism
}

\author{
Hong Tan ${ }^{1, *(D)}$, Guohua Cao ${ }^{1}$, Yu $\mathrm{He}^{2}$ and Yujia $\mathrm{Lu}^{3}$ \\ 1 Economics and Business Administration College, Chongqing University, Chongqing 400044, China; \\ caoguohua@cqu.edu.cn \\ 2 School of Public Affairs and Administration, University of Electronic Science and Technology of China, \\ Chengdu 611731, China; 2019160901020@std.uestc.edu.cn \\ 3 School of Economics and Business Administration, Southwest University of Science and Technology, \\ Mianyang 621010, China; luyujia@swsut.edu.cn \\ * Correspondence: tanhong@swust.edu.cn
}

check for

updates

Citation: Tan, H.; Cao, G.; He, Y.; $\mathrm{Lu}, \mathrm{Y}$. Channel Structure Choice for Remanufacturing under Green Consumerism. Processes 2021, 9, 1985. https://doi.org/10.3390/pr9111985

Academic Editor: Ying (Gina) Tang

Received: 14 October 2021

Accepted: 5 November 2021

Published: 7 November 2021

Publisher's Note: MDPI stays neutral with regard to jurisdictional claims in published maps and institutional affiliations.

Copyright: (c) 2021 by the authors. Licensee MDPI, Basel, Switzerland. This article is an open access article distributed under the terms and conditions of the Creative Commons Attribution (CC BY) license (https:// creativecommons.org/licenses/by/ $4.0 /)$.

\begin{abstract}
In recent decades, more and more consumers-referred to as "green consumers"—are willing to incorporate environmentally responsible decisions into their purchasing behaviors. This tendency is particularly notable in the European Union, the USA, and China. From a research perspective, while recent studies on remanufacturing have investigated optimal practices in regard to green consumerism, they have failed to address the flexibility manufacturers are afforded to outsource remanufacturing operations to third parties. In practice, some brand-name manufacturers-such as IBM, Land Rover, and Sun-do indeed outsource their remanufacturing operations. To further our understanding of the implications of differentiated structures for remanufacturing operations under green consumerism, we developed two models: one for a manufacturer undertaking remanufacturing themselves (Model M), and one for a manufacturer outsourcing it to a third-party remanufacturer (Model O). Our results indicate that, for markets with significant green consumerism, Model M tends to result in more remanufactured units and creates higher profitability for the manufacturer. However, under certain conditions, this model may also result in greater harm to the environment due to the comparative excess of manufacturers in the remanufacturing process. This implies that environmental groups and agencies should not only aim to encourage green consumerism, but should also focus their attention on the channel structures for remanufacturing.
\end{abstract}

Keywords: sustainable supply chain; remanufacturing; green consumerism; channel structure

\section{Introduction}

Environmental problems-including rising land and ocean temperatures, melting glaciers, unusual weather patterns, etc.- have increased significantly over the last few hundred years. There is mounting evidence that the abovementioned environmental problems began around the time of the Industrial Revolution and may be related to the subsequent increased consumption of fossil fuels. For example, research on near-surface temperatures over land and oceans indicates that marked warming occurred during the first half of this century, with relatively steady temperatures thereafter until the mid-1970s, and rapid warming returning during the 1980s [1]. As such, the possible solutions afforded by green manufacturing are emerging as one potential avenue with which to reduce carbon intensity and other production waste, and to enhance the utilization of energy and natural resources [2]. Accordingly, more and more counties and environmental entities are sparing no effort in encouraging firms to change their traditional industrial patterns to mitigate the resultant environmental impacts. For instance, the European Union announced the Waste Electrical and Electronic Equipment (WEEE) directive to promote "extended producer responsibility" and committed to reduce carbon dioxide emissions by $40 \%$ by 2030 [3]. Similarly, in 2020, China promised that it would strive to peak its carbon dioxide emissions by 2030 and achieve carbon neutrality by 2060 [4]. 
Remanufacturing is the process of collecting used items, extracting the useful parts, and reusing these parts in the production of new products [5]. When compared with producing new products from raw materials alone, remanufacturing is more profitable for firms. Overall, the unit manufacturing cost when utilizing remanufacturing is about $40-60 \%$ of that of a new product [6,7]. In 1991, Xerox successfully saved more than 200 million USD by remanufacturing copiers that were returned at the end of their lease contracts [7]. In addition to increased profitability, remanufacturing can be beneficial to the environment due to reduced waste creation. It is estimated that, in 1996, Ford prevented the disposal of more than 67,700 pounds of toner cartridges through use of a remanufacturing program $[5,7]$.

Since remanufacturing offers both economic and environmental benefits, more and more manufacturers have developed business models that integrate remanufacturing operations into their existing manufacturing systems. For example, brand-name manufacturers in a variety of industries-e.g., Kodak and Fuji Film in single-use cameras, Xerox in toner cartridges and photocopiers, IBM and Lenovo in computers, and General Motors, the Ford Motor Company, and Volkswagen in automobiles-are engaged in remanufacturing operations. According to one survey, it is estimated that remanufacturing operations will grow to represent more than 45 billion USD per year and support 180,000 full-time jobs by 2021 [8].

More importantly, consumers are aware of environmental issues and are willing to incorporate environmental responsibility into their purchasing behaviors [9]. These consumers are usually referred to as "green consumers": consumers with a personal ethical orientation or a set of personal pro-environmental values and attitudes that inform a particular form of socially conscious or socially responsible decision making [10]. According to a survey on the European Union market, more than $75 \%$ of respondents would be willing to pay a premium for products with environmentally friendly features absent in traditional products [11]. This tendency can also be observed in China: by the end of 2015, China's green consumers numbered 65 million and contributed a reduction in carbon dioxide emissions of 30 million tons [12]. Green consumerism is becoming increasingly important to firms, as it considers both environmental and economic perspectives [13].

A natural question that arises is whether green consumerism due to environmental considerations is desirable from the economic perspective of manufacturers. Intuitively, the manufacturer would benefit from a new revenue stream from remanufacturing, as green consumers are willing to pay more for remanufactured products than traditional consumers are. For example, a survey from Tully and Winer [14] revealed that upwards of $60 \%$ of green consumers would pay a premium of $16.8 \%$ over the price traditional consumers are willing to pay. Thus, appealing to green consumers could result in greater profits for companies that adopt remanufacturing practices.

However, it should be noted that decisions regarding remanufacturing are more involved when the potential cannibalization of new product sales is considered. For example, Hewlett-Packard remanufactures very few of its returned items as they firmly believe that for every four remanufactured sales, one new sale is cannibalized [15]. Naturally, the adoption of remanufacturing could have a net negative effect on a manufacturer's profitability from new producing due to a reduction in new product sales. As such, rather than undertake the remanufacturing operation themselves, many brand-name manufacturerse.g., IBM, Land Rover, and Sun-outsource this process to third-party remanufacturers. According to a survey by Hauser and Lund [16], of 2000 remanufacturing firms in the US market, only $6 \%$ of them were OEMs.

Although recent studies on remanufacturing have investigated optimal practices in regard to green consumerism (see, e.g., [17-19]), the available research assumes that manufacturers are responsible for remanufacturing, and thus ignores the fact that they have the flexibility to outsource remanufacturing operations to third parties. However, decisions concerning whether a manufacturer should undertake remanufacturing themselves or outsource it to a third-party remanufacturer remain a fundamental problem in operation 
management. In particular, some consumers may associate the third-party remanufactured product with the manufacturer's brand $[13,20]$. As such, to help firms make optimal strategic decisions, it is essential to have a comprehensive understanding of the implications of differentiated structures for remanufacturing operations under green consumerism.

To this end, we developed two models: one in which the manufacturer undertakes the remanufacturing process themselves (Model M), and one in which it is outsourced to a third-party remanufacturer (Model O). In both models, all consumers are divided into two types: green consumers, who care about the environmental impact of the product, and newness-conscious consumers, who focus on the newness of the product. We used these models to answer the following research questions:

(1) From a decision-making perspective, what are the implications of green consumerism?

(2) From a profitability perspective, what are the optimal strategic decisions for manufacturers?

(3) From an environmental performance perspective, what are the optimal strategic decisions for environmental groups?

(4) From a consumer behavior perspective, what are the optimal strategic decisions for the welfare of consumers?

Our results indicate that, for markets with significant green consumerism, manufacturers would sell fewer new products but more remanufactured units under the scenario in which they undertake remanufacturing themselves, when compared with the scenario in which they outsource remanufacturing to third parties. This difference in the quantities of both products sold increases with the degree of green consumerism. More importantly, our results demonstrate that, whether due to economic or environmental benefits, remanufacturing undertaken by the manufacturer is always an advantageous strategy.

The remainder of this paper is organized as follows: Section 2 reviews the related literature; Section 3 describes the key elements and formulates two models-Model M and Model O; Section 4 provides an analysis of the main results; and Section 5 concludes the paper and suggests future research directions.

\section{Literature Review}

Our work is primarily related to three streams of research. The first examines the implications of channel structure on remanufacturing, the second considers green consumerism, and the third investigates remanufacturing policies (a quick overview of this paper's contributions is presented in Table 1).

Table 1. Overview of this paper's contribution to related research.

\begin{tabular}{cccc}
\hline Author(s) & $\begin{array}{c}\text { Remanufacturing } \\
\text { Structures }\end{array}$ & GreenConsumerism & $\begin{array}{c}\text { Remanufacturing } \\
\text { Policies }\end{array}$ \\
\hline $\begin{array}{c}\text { Lei et al. [21], Zou et al. } \\
\text { [22], Yang et al. [23], } \\
\text { Kushwaha et al. [24] }\end{array}$ & $\sqrt{ }$ & $\mathbf{x}$ & $\mathbf{X}$ \\
\hline $\begin{array}{c}\text { Gleim et al. [9], } \\
\text { Wen et al. [18], } \\
\text { Zhang and He [19] }\end{array}$ & $\mathbf{x}$ & $\sqrt{ }$ & $\sqrt{ }$ \\
\hline $\begin{array}{c}\text { Webster [25], } \\
\text { Hong et al. [26], } \\
\text { Mitra and Webster [27], } \\
\text { and Han et al. [28] }\end{array}$ & $\mathbf{x}$ & $\mathbf{x}$ & \\
\hline This paper & $\sqrt{ }$ & $\sqrt{ }$ \\
\hline
\end{tabular}

The first stream of research is related to channel structures for remanufacturing. For example, Lei et al. [21] constructed two models, one with and one without remanufacturing, to determine the optimal levels of carbon emission reduction and pricing strategies under different channel structures so that the manufacturer can produce/remanufacture products 
and sell them at the same price through either their own direct channel or through retail channels. Meanwhile, Zou et al. [22] compared two models where the original equipment manufacturers allowed third-party remanufacturers to perform remanufacturing operations of branded or patented products - through either outsourcing or authorizationand demonstrated that, when consumers perceive the remanufactured products to be of lower value, third-party remanufacturers prefer the authorization approach. However, Yang et al. [23] investigated a remanufacturing closed-loop supply chain under the cap-andtrade regulation, where the collection operation could be carried out by a manufacturer, a retailer, or a third party, and indicated that remanufacturing can effectively decrease carbon emissions and increase profits for both the manufacturer and the retailer. Similarly, Kushwaha et al. [24] proposed a mixed-integer linear programming model to help manufacturers decide on an optimal combination of channels for collecting used products from specific regions in a finite multi-period situation under constraints regarding the quantity and quality of returned products, and carbon emissions. Yang et al. [29] focused on an $\mathrm{O} 2 \mathrm{O}$ retail supply chain in the context of a low-carbon environment under three scenarios: without cap-and-trade regulation, with cap-and-trade regulation based on a grandfathering mechanism, and with cap-and-trade regulation based on a benchmarking mechanism. Although the above studies investigated the impact of different operation channels on remanufacturing, they fail to highlight channel selection strategies for remanufacturing in light of green consumerism. Thus, we complement them by providing a comprehensive investigation into the implications of differentiated structures for remanufacturing operations under green consumerism.

The second research stream concerns remanufacturing decisions under green consumerism. For example, Gleim et al. [9] presented a critical incident qualitative study and two quantitative studies to examine the factors associated with non-green purchasing behaviors. Wen et al. [18] investigated the channel choice of an independent remanufacturer who considered whether to add a direct channel to its existing retail channel in the presence of environmentally responsible consumers and found that a higher proportion of green consumers strengthened the remanufacturer's motivation to add a direct channel. Zhang and He [19] considered a centralized system consisting of a manufacturer and a retailer, in which returned products are repaired and resold as green remanufactured items in the second selling period, and revealed that remanufacturing activity can increase the whole system's green profits, despite cannibalizing new product sales. As mentioned earlier, while recent research has investigated optimal practices under green consumerism, it assumes that manufacturers are responsible for remanufacturing and thus ignore the flexibility afforded to manufacturers to outsource remanufacturing operations to third parties. To this end, we formulated two models: one in which the manufacturer undertakes remanufacturing themselves, and one in which it is outsourced to a third-party remanufacturer. Furthermore, we address the implications of differentiated structures for remanufacturing operations under green consumerism.

Our research also relates to remanufacturing policies. Webster [25] developed a general two-period model to investigate questions of interest to policy-makers in government and managers that related the impact of take-back laws within a manufacturer/remanufacturer competitive framework. Hong et al. [26] studied a dual-mode production planning problem with emission constraints, where a manufacturer produces a single product with two optional technologies and demonstrated that the manufacturer's decisions and benefits were significantly affected by emission caps under the mandatory emission-cap policy. In particular, several authors-including Mitra and Webster [27], Han et al. [28], and Mahmoudi et al. [30] - have highlighted the impact of subsidies from environmental groups and agencies. Although the above literature strives to explore the impact of remanufacturing policies on green consumerism, there is little attention paid to channel structures for the remanufacturing process. Therefore, we complement them by providing a deeper understanding of remanufacturing channel structures to assist environmental groups and agencies. In particular, we determined that, for markets with significant 
green consumerism, the adoption of in-house remanufacturing usually results in more remanufactured units sold and higher profitability, but may lead to greater environmental harm due to the comparative excess of manufacturers in the remanufacturing process.

\section{Problem Description}

This paper highlights a remanufacturing system with two risk-neutral parties: a manufacturer and a third-party remanufacturer. The manufacturer is the original equipment manufacturer who provides all new products and determines whether to undertake the remanufacturing itself (Model $\mathrm{M}$ ) or outsource it to a third-party remanufacturer (Model $\mathrm{O})$. in Model M, the manufacturer determines the optimal quantities of new and remanufactured products. However, in Model $\mathrm{O}$, the manufacturer first sets a patent license fee (i.e., $f$ ) for the third-party remanufacturer if the remanufacturing is outsourced. In this model, the manufacturer and the remanufacturer would determine the optimal quantities of new and remanufactured products, respectively.

Given the above basic framework, we next introduce our notation and lay out our assumptions.

Assumption 1. The manufacturer acts as a Stackelberg leader, while the third-party remanufacturer is the follower. The information between them is complete information.

Similar to Yang et al. [23] and Wei et al. [31], we assume that the information between the manufacturer and the third-party remanufacturer is completely symmetrical. It should be noted that this assumption of complete information allows both parties to access the same information and to control the risk-sharing issues.

Assumption 2. All remanufactured products are derived from new product sales.

Assumption 2 is quite common in remanufacturing literature (see, e.g., Agrawal et al. [32] and Zhang et al. [33]). Consistent with prior studies, we assume that, for any given unit, there are two lives: the initial sale and use as a new product and the subsequent sale and use as a remanufactured product. This assumption restricts a firm to obtaining remanufacturing materials at the end of the lifecycle of new products and is consistent with historical trends in remanufacturing [31].

Assumption 3. Consumers can be divided into two types: one being green-conscious consumers, with market segment $g$, who are willing to make a tradeoff between new and remanufactured units at the right price; and the other being newness-conscious consumers, with market segment $(1-g)$, who prefer new products.

In line with the prior literature on consumer behavior in regard to remanufacturing, e.g., Ho et al. [13] and Zhou et al. [34], we divide the market into newness-conscious consumers and green-conscious consumers. It should be noted that newness-conscious consumers will not buy remanufactured products because they have a negative response to these products, including uncertainty about the product's quality [35]. In addition, we assume that all green-conscious consumer purchasing decisions can be impacted by product price-that is, they are willing to buy a remanufactured unit at a lower price [22,31,34].

Assumption 4. Consumers' willingness to pay for a new product, $v$, is uniformly distributed over the interval $(0,1)$. However, the willingness to pay for a remanufactured unit is $k \in(0,1)$ of that of the new one.

Assumption 5. Each consumer buys at most one product. The unit patent fee, retail price, and quantity of new and remanufactured products are $f, p_{i}$, and $q_{i}$, respectively, where the subscript $i \in\{n, r\}$ refers to the new and remanufactured products. 
Based on Assumptions 3-5, we can obtain the following inverse demand functions (see Appendix A for the detailed derivation):

$$
\begin{aligned}
& p_{n}=1-q_{n}-k q_{r} \\
& p_{r}=k\left(1-q_{n}-k q_{r}\right)-k(1-k) q_{r} / g
\end{aligned}
$$

Assumption 6. The unit process cost of product $i$ is $c_{i}$.

According to Wei et al. [31] and Zhou et al. [34], we assume that the process costs for new products are $c_{n}=c<1$, while the process costs for remanufactured products are $c_{r}<c_{n}$.

Assumption 7. In both models, all decisions are considered in a single-period setting.

This assumption states that the used cores previously existed in the market and can be collected for remanufacturing - that is, similar to Wei et al. [31], Zhou et al. [34], and Savaskan et al. [36], we can highlight the average profits per period.

All the definitions of the variables are shown in Table 2.

Table 2. Notations.

\begin{tabular}{cc}
\hline Nomenclature & Definition \\
\hline$g$ & The market segment of green consumers \\
$c_{i}$ & Unit process cost of product $i, i \in\{n, r\}$ \\
$k$ & Value discount for remanufactured products \\
$p_{i}^{b}$ & Prices of product $i$ in Model $b, b \in\{M, O\}$ \\
$q_{i}^{b}$ & Quantities of product $i$ in Model $b, b \in\{M, O\}$ \\
$f$ & Unit patent fee charged to outsourced remanufacturers \\
$\pi_{a}^{b}$ & Player a/s profit in Model $b, a \in\{m, r\}, b \in\{M, O\}$ \\
$E^{b}$ & Environmental impacts in Model $b, b \in\{M, O\}$ \\
\hline
\end{tabular}

\section{Problem Solution}

In this section, we derive the equilibrium of both channel structures-Model M and Model $\mathrm{O}-$ using $\pi_{a}^{b}$ to represent the profit for player $a$ under channel structure $b$, where subscript $a \in\{m, r\}$ denotes the manufacturer and the third-party remanufacturer, respectively, while the superscript $b \in\{M, O\}$ denotes Model M and Model O, respectively.

\subsection{Model M}

In Model $\mathrm{M}$, the manufacturer produces new products and also engages in remanufacturing. Note that such a model is consistent with the fact that many manufacturers-such as Xerox, Kodak, and the Ford Motor Company-have conducted remanufacturing operations for many years.

The profit function of the manufacturer in Model $\mathrm{M}$ can be expressed as:

$$
\max _{q_{n}, q_{r}} \pi_{m}^{M}=\left(p_{n}-c_{n}\right) q_{n}+\left(p_{r}-c_{r}\right) q_{r}
$$

The first term in Equation (2) is the profitability from new products, while the second term is the profitability from remanufacturing. Substituting the inverse demand functions of (1) into (2), we can solve the above objective function and obtain the equilibrium decisions and profits, which are summarized in Table 3 (for clarity, its proofs are provided in Appendix B). 
Table 3. Equilibrium decisions and profits.

\begin{tabular}{|c|}
\hline Remanufacturing Undertaken by Manufacturer (Model M) \\
\hline $\begin{array}{c}q_{n}^{M}=\frac{1-k+g c_{r}-k g c_{n}-c_{n}+k c_{n}}{2(1-k)} \\
p_{n}^{M}=\frac{1+c_{n}}{2} \\
q_{r}^{M}=\frac{g\left(k c_{n}-c_{r}\right)}{2 k(1-k)} \\
p_{r}^{M}=\frac{k+c_{r}}{2} \\
\pi_{m}^{M}=\frac{2 k^{2} c_{n}-k^{2}-k^{2} c_{n}^{2}+k^{2} g c_{n}^{2}+k+k c_{n}^{2}-2 k c_{n}-2 c_{r} g k c_{n}+g c_{r}^{2}}{4 k(1-k)}\end{array}$ \\
\hline Remanufacturing Undertaken by a Third-Party Remanufacturer (Model O) \\
\hline $\begin{array}{c}f=\frac{5 k^{2} g+8 k-8 k^{2}-4 k c_{r} g-k^{2} g c_{n}-8 c_{r}+8 k c_{r}}{25(5 k+8-8 k)} \\
q_{n}^{O}=\frac{8-7 k g c_{n}+5 k g+8 k c_{n}-8 k+2 g c_{r}-8 c_{n}}{10 k+16-16 k} \\
p_{n}^{O}=\frac{3 k g c_{n}+5 k g-8 k c_{n}-8 k+2 c_{r} g+8 c_{n}+8}{10 k g+16-16 k} \\
p_{r}^{O}=\frac{3 k^{2} g c_{n}+5 k^{2} g-4 k^{2} c_{n}-8 k k^{2}+2 c_{r} g k-4 k c_{r}+8 k+4 k c_{n}+4 c_{r}}{10 k g+16-16 k}\end{array}$ \\
\hline $\begin{array}{c}\pi_{m}^{O}=\frac{9 k^{2} g c_{n}^{2}+5 k^{2} g-10 k^{2} g c_{n}+16 k^{2} c_{n}-8 k^{2}-8 k^{2} c_{n}^{2}-8 g k c_{n} c_{r}-16 k c_{n}+8 k+8 k c_{n}^{2}+4 g c_{r}^{2}}{4 k(5 k g+8-8 k)} \\
\pi_{r}^{O}=\frac{4 g(k g-k+1)\left(k c_{n}-c_{r}\right)^{2}}{4 k(5 k g+8-8 k)^{2}}\end{array}$ \\
\hline
\end{tabular}

Based on the outcomes in Table 3, we find that green consumerism plays an important role in determining the equilibrium decisions (Its proofs are provided in Appendix C). In particular,

Proposition 1. As the green consumerism increases, the optimal quantities of new (remanufactured) products decrease (increase), that is, $\frac{\partial q_{n}^{M}}{\partial g}<0\left(\frac{\partial q_{r}^{M}}{\partial g}>0\right)$.

Not surprisingly, remanufacturing operations create potential cannibalization problems that can affect new product sales [15,20,22]. However, Proposition 1 further reveals that, when a manufacturer engages in remanufacturing, the optimal quantity of remanufactured products increases with the market segment of green consumers, $g$. This means that a market with significant green consumerism is indeed beneficial for remanufacturing. Therefore, as the degree of green consumerism increases, remanufacturing becomes a more profitable business. Original manufacturers would, then, like to increase the quantities of remanufactured products produced. However, Proposition 1 also shows that the optimal number of new units decreases with $g$. This means that a market with increased green consumerism would show decreased new product sales due to the cannibalization from remanufacturing. Although remanufacturing can create additional profits for the manufacturer as green consumerism increases, new product sales would be significantly and negatively impacted.

\subsection{Model O}

In Model $\mathrm{O}$, the manufacturer produces new products but outsources remanufacturing operations to a third-party remanufacturer. Note that Model $\mathrm{O}$ is consistent with the fact that many brand-name manufacturers-e.g., IBM, Land Rover, and Sun-outsource this process to third-party remanufacturers. For instance, rather than undertaking the remanufacturing operation in-house, IBM outsources its remanufacturing to third-party remanufacturers through certification programs in which all remanufactured IBM equipment is inspected by IBM engineers who grant a seal of approval. 
Then, in Model O, the manufacturer's problems are:

$$
\begin{aligned}
\max _{f} \pi_{m}^{O} & =\left(p_{n}-c_{n}\right) q_{n}+f q_{r} \\
\max _{q_{n}} \pi_{m}^{O} & =\left(p_{n}-c_{n}\right) q_{n}+f q_{r}
\end{aligned}
$$

where the first term is the profitability from new products and the second term is the profitability of outsourcing remanufacturing operations.

Anticipating the response of $f^{*}$ and $q_{n}^{O *}$, the third-party remanufacturer's problem is:

$$
\max _{q_{r}} \pi_{r}^{O}=\left(p_{r}-f-c_{r}\right) q_{r}
$$

Solving these problems with backward induction, we summarize the equilibrium decisions in Table 3 (Its proofs are provided in Appendix D).

To ensure that all outcomes in Table 3 are positive and $q_{r}<q_{n}$, we offer the following additional assumption:

Assumption 8. All parameters and variables in this paper must satisfy non-negativity constraints, that is, we only consider $c_{r}<k c_{n}$ and $g<\frac{(1-k) k\left(1-c_{n}\right)}{k c_{n}+k^{2} c_{n}-k c_{r}-c_{r}}$.

We now can ascertain the important role green consumerism plays in determining the equilibrium decisions under Model $\mathrm{O}$ - that is, we offer the following proposition (Its proofs are provided in Appendix E):

Proposition 2. As green consumerism increases, the optimal quantities of new (remanufactured) products decrease (increase), that is, $\frac{\partial q_{n}^{O}}{\partial g}<0\left(\frac{\partial q_{r}^{O}}{\partial g}>0\right)$.

Similar to Proposition 1, Proposition 2 shows that, when a manufacturer outsources its remanufacturing to a third party, green consumerism is beneficial to the remanufacturer, but negatively impacts new product sales. The intuition behind this is analyzed in Proposition 1 and thus is not repeated here.

\section{Problem Analysis}

In this section, we intend to answer the questions posed at the beginning of this paper. To do so, we need to compare the differences between both models, which is summarized below.

\subsection{Comparison of Optimal Decisions}

Based on the outcomes in Table 3, we are in a position to address the differences in the optimal quantities of both products under Model M and Model O. We first highlight the differences in the optimal quantities of remanufactured products under both models as follows (Its proofs are provided in Appendix F):

Proposition 3. The optimal quantity of remanufactured products in Model M is higher than that in Model O; i.e., $q_{r}^{M}>q_{r}^{O}$; moreover, $\partial\left(q_{r}^{M}-q_{r}^{O}\right) / \partial g>0$.

Proposition 3 reveals that outsourcing remanufacturing to a third party leads to lower quantities of remanufactured products. This can be explained as follows: Based on Equations (2)-(4), we find that, when remanufacturing is outsourced to a third party, the manufacturer charges a patent license fee $(f)$ to the third-party remanufacturer. Naturally, under this scenario, the third party would always bear the costs of $f+c_{r}$ for unit remanufacturing. However, when the remanufacturing is undertaken by the manufacturer in Model $\mathrm{M}$, the cost of remanufacturing is $c_{r}$. Obviously, outsourcing remanufacturing to a third party leads to traditional double-marginalization problems between the upstream agent (i.e., the manufacturer) and the downstream agent (i.e., the third-party remanufac- 
turer). Such double-marginalization problems result in higher retail prices and lower sale quantities than those in Model M (as it is a vertically integrated model) [37].

Recall that Propositions 1 and 2 demonstrated that, whether the remanufacturing is undertaken by the manufacturer (Model M) or by a third-party remanufacturer (Model O), as green consumerism (i.e., $g$ ) increases, the optimal quantity of remanufactured products in both models also increases (i.e., $\partial q_{r}^{M} / \partial g>0, \partial q_{r}^{O} / \partial g>0$ ). However, as indicated in Figure 1, Proposition 3 further shows that as green consumerism increases, the difference in the optimal quantities of remanufactured products in both models increases $\partial\left(q_{r}^{M}-q_{r}^{O}\right) / \partial g>0$. This can be interpreted as follows: Based on the optimal patent license in Table 1, we find that $\partial f / \partial g=\frac{4 k(1-k)\left(k c_{n}-c_{r}\right)}{(5 k g+8-8 k)^{2}}>0$ - that is, as green consumerism increases, the manufacturer charges a higher patent license fee for the outsourced remanufacturing. Such a higher patent license fee leads to a greater double-marginalization problem between the manufacturer and the third-party remanufacturer. Naturally, in Model $\mathrm{O}$, the greater the double-marginalization, the less remanufactured products are sold. Thus, as green consumerism increases, the difference in the optimal quantities of remanufactured products under both models increases.

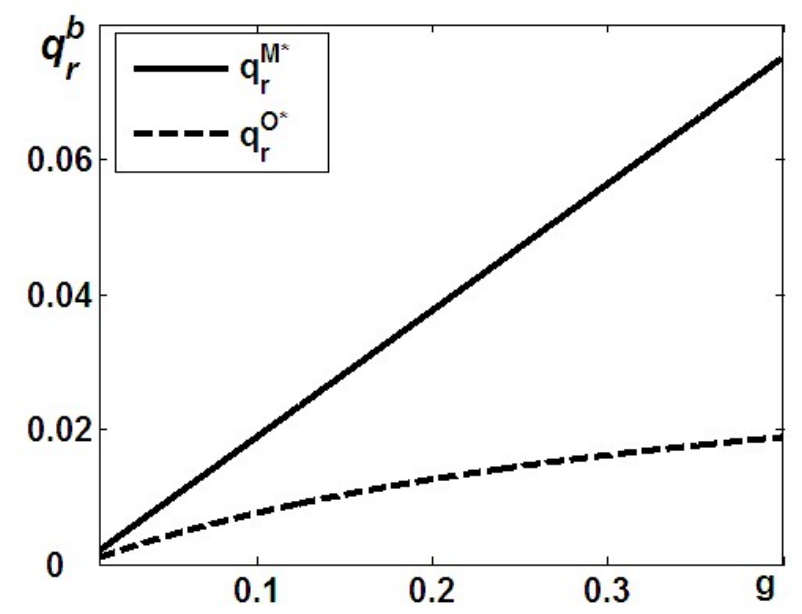

Figure 1. Effect of $g$ on $q_{r}^{b}$.

We now highlight the differences in the optimal quantities of new products under both models. Based on the outcomes of Table 3, we provide the following proposition (Its proofs are provided in Appendix G):

Proposition 4. The optimal quantity of new products in Model M is lower than that of Model O; i.e., $q_{n}^{M}<q_{n}^{O}$; moreover, $\partial\left(q_{n}^{M}-q_{n}^{O}\right) / \partial g<0$.

As shown in Figure 2, Proposition 3 reveals that, when outsourcing remanufacturing to a third party, the manufacturer provides more new units than in Model M. It should be noted that, when outsourcing the remanufacturing to a third party, new products are produced by the manufacturer but all remanufactured products are offered by a thirdparty remanufacturer. Thus, in Model $\mathrm{O}$, the manufacturer adopts two major methods to deal with the cannibalization problem due to remanufacturing: On the one hand, the manufacturer usually increases the remanufacturing costs by charging a patent license fee $(f)$ to the third-party remanufacturer. On the other hand, the manufacturer provides more new products, which results in a smaller potential market for remanufactured products. In contrast, when remanufacturing is undertaken by the manufacturer, the manufacturer can take initiative by reducing the number of new units produced to obtain higher profits from remanufacturing, which means that the potential market and the marginal revenue from remanufacturing are both higher. 


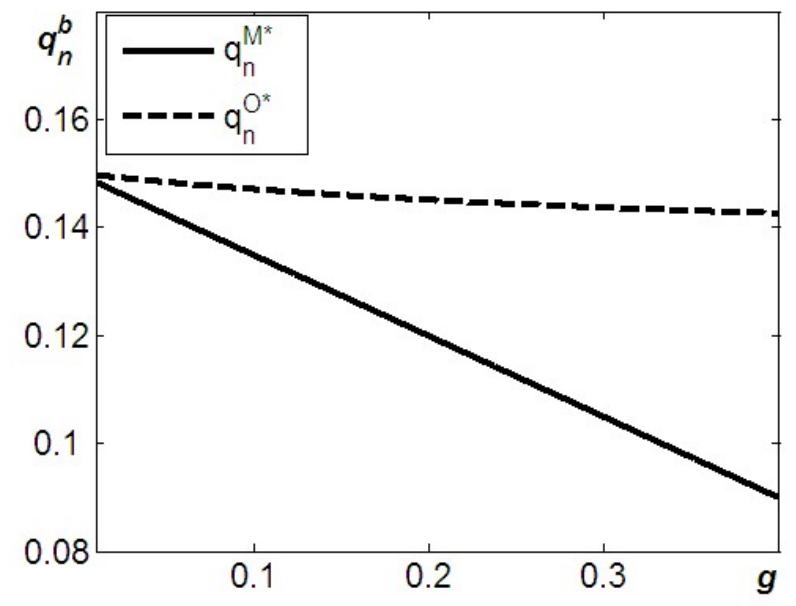

Figure 2. Effect of $g$ on $q_{n}^{b}$.

The optimal quantity of remanufactured products increases under both models with increased green consumerism. Recall that, as green consumerism increases, the patent license fee $(f)$ to the third-party remanufacturer increases-that is, $\partial f / \partial g>0$. This means that, as green consumerism increases, there is greater double-marginalization between both parties in Model O. Confronting a greater double-marginalization problem, the remanufacturer provides fewer remanufactured units than are produced in Model M. Thus, as Figure 2 shows, the reducing rate in the quantity of new products produced in Model M is less than that in Model O.

\subsection{Comparison of Optimal Profitability}

In the analysis thus far, we have answered the first research question from the manufacturer's perspective. We now analyze the optimal strategic decisions for the manufacturer's profitability. Based on the outcomes in Table 3, we summarize this profitability in the following proposition (Its proofs are provided in Appendix $\mathrm{H}$ ):

Proposition 5. The manufacturer's profitability in Model $M$ is higher than that in Model O; i.e., $\pi_{m}^{M}>\pi_{m}^{O}$; moreover, $\partial\left(\pi_{m}^{M}-\pi_{m}^{O}\right) / \partial g>0$.

Proposition 5 shows that the manufacturer benefits more in Model $\mathrm{M}$ than in Model $\mathrm{O}$. To understand the rationale behind this difference in the manufacturer's profits, we should recall that, as Proposition 3 demonstrated, outsourcing remanufacturing to a third party leads to lower quantities of remanufactured products due to traditional doublemarginalization problems between the two parties. Therefore, such double-marginalization problems between the manufacturer and the remanufacturer would result in lower profitability for the manufacturer in Model O than in Model M. Furthermore, in Model O, the remanufacturing is undertaken by a third-party remanufacturer, but all new products are offered by the manufacturer. However, in Model M, the manufacturer has a monopoly on the product and provides both new and remanufactured products. As such, the inherent competition in Model O would lead to even lower profits than in Model M. Therefore, as shown in Figure 3, the manufacturer benefits more in Model M than in Model O-that is, confronting a market with green consumerism, the manufacturer always prefers Model M over Model O. 


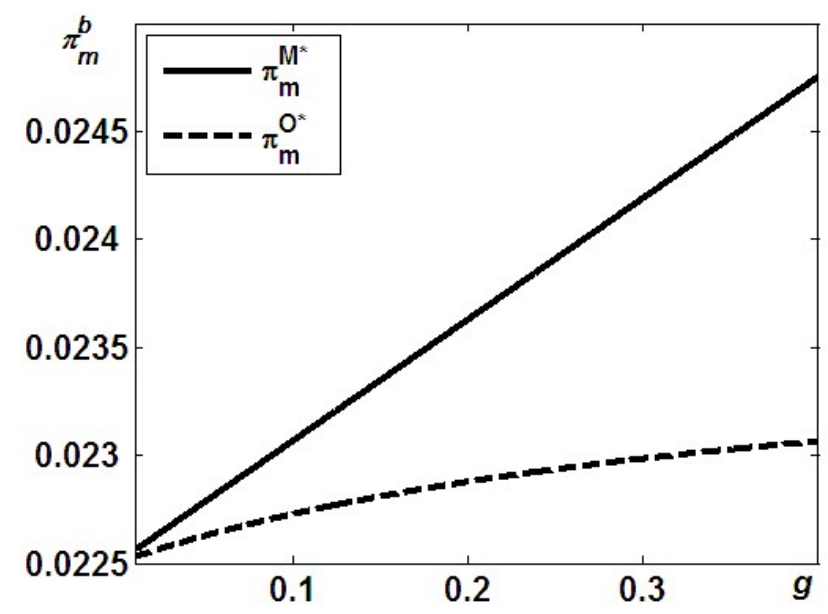

Figure 3. Effect of $g$ on $\pi_{m}^{b}$.

Proposition 5 further shows that, as Figure 3 demonstrated, the difference in profitability between Model $\mathrm{M}$ and Model $\mathrm{O}$ increases with green consumerism. This can be interpreted as follows: On the one hand, as green consumerism increases, remanufacturing becomes a more profitable business. In addition, the fiercer competition in Model $\mathrm{O}$ would further impact the profitability of the manufacturer. On the other hand, as green consumerism increases, the patent license fee $(f)$ to the third-party remanufacturer increases. The increase in the remanufacturing costs in Model $\mathrm{O}$ would result in less profitability for the manufacturer. As such, as shown in Figure 3, as green consumerism increases, the difference in profitability between Model $\mathrm{M}$ and Model $\mathrm{O}$ increases.

It is interesting to note that, as Proposition 5 suggests, for a market with green consumerism, a manufacturer would like to undertake remanufacturing operations by itself. This may be consistent with the fact that, rather than outsourcing operations to third-party remanufacturers, some brand-name manufacturers attempt to adopt remanufacturing themselves. For example, in April of 2004, Canon filed a lawsuit against Recycle Assist, arguing that the import and sale of recycled ink cartridges by Recycle Assist infringed upon its patent (jp3278410), and required that the latter party stop the import and sale of recycled Cannon ink cartridges and discard their existing inventory.

\subsection{Comparison of Environmental Performance}

In this subsection, we address the third research question, which regards the optimal strategic decision for environmental groups from the perspective of environmental performance.

Similar to Atasu and Souza [38] and Agrawal et al. [39], we divide the environmental performance per product into four life-cycle phases: production, use, disposal, and remanufacturing, defined as $i_{p}, i_{u}, i_{d}$, and $i_{s}$, respectively. We then summarize the total environmental impact as $E=i_{p} q_{n}+i_{u}\left(q_{n}+q_{r}\right)+i_{d} q_{n}+i_{s} q_{r}=\left(i_{p}+i_{u}+i_{d}\right) q_{n}+\left(i_{u}+i_{s}\right) q_{r}$. For simplification, we further assume that $E=i_{n} q_{n}+i_{r} q_{r}$.

Given that $E^{b}$ denotes the total environmental impact in Model $b, b \in\{M, O\}$, we answer the last question as follows (Its proofs are provided in Appendix I):

Proposition 6. There is a threshold value $g_{0}$ for green consumerism below which the total environmental impact in Model $M$ is lower than that in Model O; i.e., $E^{M}<E^{O}$; otherwise, the opposite is true.

Recall that, based on Propositions 3 and 4, we can conclude that, when the manufacturer undertakes remanufacturing, it always provides more remanufactured (and less new) products than when outsourcing remanufacturing to third-party remanufacturers; i.e., $q_{r}^{M}>q_{r}^{O}\left(q_{n}^{M}<q_{n}^{O}\right)$. In addition, as green consumerism increases, remanufacturing becomes a more profitable business. As such, and as Figure 4 indicates, when green con- 
sumerism is not pronounced, i.e., $g<g_{0}$, the greater remanufacturing of Model M results in lower total environmental impact than in Model O; i.e., $E^{M}<E^{O}$. In contrast, when green consumerism is pronounced, i.e., $g>g_{0}$, the total environmental impact in Model $\mathrm{M}$ is greater than that in Model O; i.e., $E^{M}>E^{O}$.

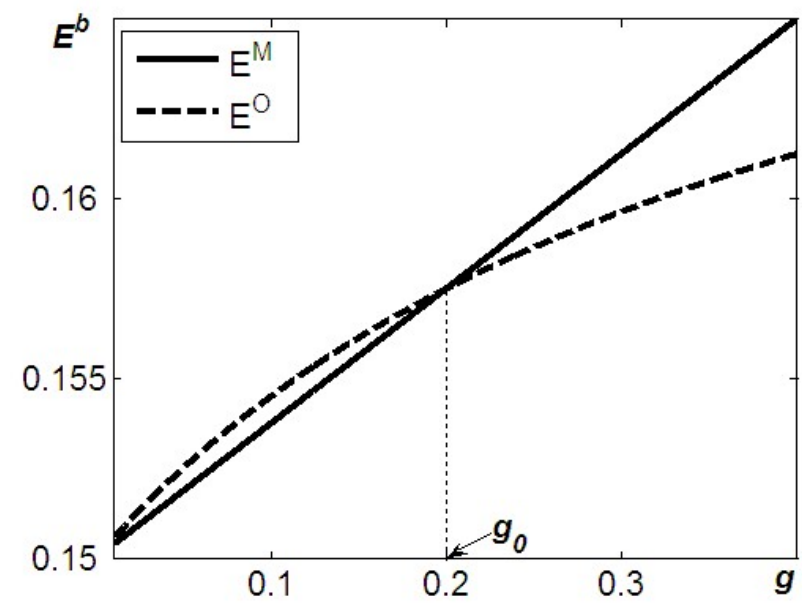

Figure 4. Effect of $g$ on $E^{b}$.

Proposition 6 implies that environmental groups and agencies should not only pay attention to methods to encourage green consumerism, but should also focus on the channel structures for remanufacturing. In particular, when green consumerism is pronounced, outsourcing remanufacturing to third-party remanufacturers would be beneficial to our environment. For instance, in 2007, the Chinese central government initiated a pilot program to encourage some third-party remanufacturers-such as Changli, Yunnei Power, and Bestech-to engage in the remanufacturing of automotive parts, engineering machinery, and machine tools [34,39].

\subsection{Comparison of Consumer Welfare}

It should be noted that the consumer surplus, $c s^{b}$, can be divided into two parts: the newness-conscious consumers always purchase new products, and, as such, their consumer surplus can be calculated as $N c s^{b}=(1-g) \int_{1-q_{n}}^{1}\left(v-p_{n}\right) d v$, while the green consumers choose between new and remanufactured products, and, thus, their consumer surplus can be calculated as $G c s^{b}=g\left(\int_{1-q_{n}-q_{r}}^{1-q_{n}}\left(k v-p_{r}\right) d v+\int_{1-q_{n}}^{1}\left(v-p_{n}\right) d v\right)$. Thus, the total consumer surplus can be calculated as $c s^{b}=N c s^{b}+G c s^{b}$.

Based on the above functions, we can address the last question (Its proofs are provided in Appendix J) from the consumer behavior perspective, what are the optimal strategic decisions for consumer welfare?

Proposition 7. The consumer surplus in Model $M$ is lower than that in Model O; i.e., $c^{M}<{ }_{c s} \mathrm{O}$; moreover, $\partial\left(c s^{O}-c s^{M}\right) / \partial g>0$.

Proposition 7 presents an important result: if remanufacturing is undertaken by the manufacturer, there is a lower consumer surplus in Model $\mathrm{O}$ than in Model M. To understand the rationale behind this difference in consumer surplus, we should recall that, when outsourcing remanufacturing to a third party, all new units would be produced by the manufacturer and all remanufactured products would be offered by the third-party remanufacturer. However, when the remanufacturing operations are undertaken by the manufacturer, both products are offered by the manufacturer-that is, Model M provides a monopolistic position for the manufacturer; however, in Model $\mathrm{O}$, the manufacturer would compete with the third-party remanufacturer in the market. Naturally, as shown 
in Figure 5, the competition in Model O would be beneficial for consumer behavior and increase their consumer surplus.

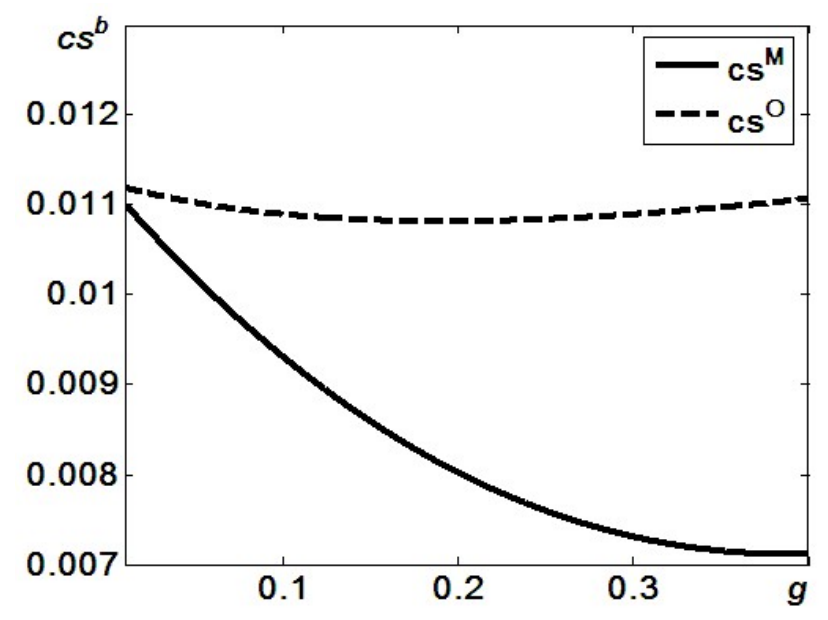

Figure 5. Effect of $g$ on $c s^{b}$.

Proposition 7 further shows that, as Figure 4 demonstrated, the difference in consumer surplus between Model $\mathrm{O}$ and Model $\mathrm{M}$ increases with green consumerism. This can be interpreted as follows: As green consumerism increases, remanufacturing becomes a more profitable business. As such, in Model $\mathrm{O}$, as green consumerism increases, the manufacturer would confront even fiercer competition from the third-party remanufacturer. Then, as demonstrated in Figure 4, as green consumerism increases, the difference in consumer surplus between Model $\mathrm{O}$ and Model $\mathrm{M}$ also increases.

\section{Discussion and Conclusions}

Over recent decades, more and more people have realized that it is necessary to change traditional industrial patterns to reduce damage to our environment. This tendency leads to more and more consumers who are willing to incorporate environmentally responsible decisions into their purchasing behaviors. These consumers are usually referred to as "green consumers" - consumers whose values and attitudes inform a particular form of socially conscious or socially responsible decision making. In practice, we observe such green consumers in the European Union, the USA, and China. As such, green consumerism is becoming increasingly important to manufacturers as it considers both environmental and economic perspectives.

From a research perspective, the interesting question that arises is whether green consumerism due to environmental considerations is desirable from the economic perspective of manufacturers. On the one hand, green consumerism can be naturally profitable for manufacturers due to the sale of remanufactured goods. On the other hand, such green consumerism could lead to fiercely adverse effects on the manufacturer's profitability from new product sales. Thus, we developed two models: one in which the manufacturer undertakes remanufacturing themselves (Model M), and one in which it is outsourced to a third-party remanufacturer (Model O). Thus, the major objective of our research was to assist companies in making optimal strategic decisions, for which it is essential to have a comprehensive understanding of the implications of differentiated structures for remanufacturing operations under green consumerism.

\subsection{Managerial Implications}

This research makes two major contributions to the literature on channel structures and green consumerism related to remanufacturing. First, although many authors (see, e.g., [21-24]) have investigated the impact of different channel structures on remanufacturing, they failed to consider the market characteristics of green consumerism. Thus, 
this paper complements them by providing an understanding of the implications of differentiated remanufacturing structures under green consumerism. Second, although recent research (see, e.g., [9,17-19]) has investigated optimal decision making under green consumerism, they assume that manufacturers are solely responsible for remanufacturing and thus ignore the flexibility of manufacturers to outsource remanufacturing operations to third parties. In this paper, we consider this possibility and further address the implications of differentiated structures for remanufacturing operations under green consumerism.

On the one hand, decisions regarding remanufacturing are more involved when the potential cannibalization effect on new product sales is considered. As such, many brandname manufacturers-e.g., IBM, Land Rover, and Sun-have outsourced remanufacturing to third parties. On the other hand, as consumers become more aware of environmental problems, they place greater importance on environmentally friendly purchases. For example, in the European Union market, more than $75 \%$ of respondents expressed a willingness to pay a premium for products with environmentally friendly features not seen in traditional products. As such, to help firms make optimal strategic decisions, it is essential to have a comprehensive understanding of the implications of differentiated structures for remanufacturing operations under green consumerism.

In particular, our results indicate that, for markets with significant green consumerism, manufacturers would provide fewer new products but more remanufactured units in the scenario in which they undertake remanufacturing themselves than in the scenario in which they outsource remanufacturing to a third party. More importantly, we find that, from an economic performance perspective, the manufacturer's profitability in Model M is always higher than in Model O. However, from the environmental performance perspective, we find that, when green consumerism is pronounced, outsourcing remanufacturing to thirdparty remanufacturers would be beneficial to the environment. As such, our analysis provides important managerial implications regarding remanufacturing policies (see, for example, [25-28]) and suggests that environmental groups and agencies should not only aim to encourage green consumerism, but should also focus on the channel structures for remanufacturing.

\subsection{Limitations and Further Research Directions}

This paper can be extended in several directions. First, in both models, we assume that all new products are produced by the manufacturer. Future research can relax this assumption to address how competition in the market for new products impacts the channel structures for remanufacturing. Second, in this paper, green consumerism is assumed to be exogenous; however, prior literature, e.g., Zhou et al. [34], demonstrated that it might be affected by consumer education regarding the environment from the manufacturer. Third, our theoretical analysis reveals that there is a threshold above which outsourcing remanufacturing to a third-party remanufacturer would be beneficial to our environment. It is of interest for further research to empirically test this hypothesis and highlight how green consumerism impacts channel structure strategies for remanufacturing.

Author Contributions: Writing—original draft preparation, H.T.; writing—review and editing, Y.L.; visualization, Y.H.; supervision, G.C. All authors have read and agreed to the published version of the manuscript.

Funding: This research was funded by Major Programs of the Sichuan Province Cyclic Economy Research Center (XHJJ-1808), the National Natural Science Foundation of China (71971043), the Special Program of the Chongqing Federation of Social Sciences (2019WT32), and the PhD and Professor Foundation of Chongqing University of Science and Technology (CK2016B06).

Institutional Review Board Statement: Not applicable.

Informed Consent Statement: Not applicable.

Data Availability Statement: All relevant data are included in the paper.

Conflicts of Interest: We declare no conflict of interest. 


\section{Appendix A. Technical Analysis for Inverse Demand}

Since all newness-conscious consumers are only conscious on the newness of the products, the utility of a new product is $N U=v-p_{n}$. On the other hand, because the green consumers care about the functionality of the products, they would make a tradeoff between the new and remanufactured products. Furthermore, based on Assumptions 3-5, the net utility for the new product would be $G U_{n}=v-p_{n}$, while the net utility for a remanufactured product is $G U_{r}=k v-p_{r}$.

Accordingly, all newness-conscious consumers have one of two options: (1) purchasing a new product; (2) keeping inactive. Then, we can find one indifferent point between purchasing a new product or keeping inactive: $v_{n i}=p_{n}$. As such, the newness-conscious consumers' demand for the new products is $D_{N n}=(1-g)\left(1-v_{n i}\right)$

However, any green consumer has one of three options: (1) purchasing a new product; (2) purchasing a remanufactured unit; or (3) keeping inactive. Then, we can find two indifferent points: one is the indifferent point between purchasing a new product or at a remanufactured one: $v_{n u}=\left(p_{n}-p_{r}\right) /(1-k)$; the other is the indifferent point between purchasing a remanufactured one and keeping inactive: $v_{u i}=p_{r} / k$. Then, the green consumers' demand for the new products is $D_{G n}=g\left(1-v_{n u}\right)$ and the demand for the remanufactured products is $D_{\mathrm{Gr}}=g\left(v_{n u}-v_{u i}\right)$.

In sum, we can get the quantities of new products to be $q_{n}=D_{N n}+D_{G n}$, while the quantities of remanufactured products are $q_{r}=D_{G r}=g\left(v_{n u}-v_{u i}\right)$. Solving these two equations, we can get the inverse demand functions as:

$$
\begin{aligned}
& p_{n}=1-q_{n}-k q_{r} \\
& p_{r}=k\left(1-q_{n}-k q_{r}\right)-k(1-k) q_{r} / g
\end{aligned}
$$

\section{Appendix B. Derivation Optimal Outcomes for Model M}

Plugging (1) into the (2), we can rewrite it as follows:

$$
\max _{q_{n}, q_{r}} \pi_{m}^{M}=\left(1-q_{n}-k q_{r}-c_{n}\right) q_{n}+\left(k\left(1-q_{n}-k q_{r}\right)-\frac{k(1-k) q_{r}}{g}-c_{r}\right) q_{r}
$$

Based on the above equation, we can obtain its first-order condition as follows:

$$
\begin{aligned}
& \partial \pi_{m}^{M} / \partial q_{n}=1-2 q_{n}-2 k q_{r}-c_{n} \\
& \partial \pi_{m}^{M} / \partial q_{r}=-2 k q_{n}-2 k^{2} q_{r}-2 q_{r} \frac{k}{g}+2 q_{r} \frac{k^{2}}{g}+k-c_{r}
\end{aligned}
$$

Solving the above equations gives the following equilibrium quantities:

$$
\begin{aligned}
q_{n}^{M} & =\frac{1-k+g c_{r}-k g c_{n}-c_{n}+k c_{n}}{2(1-k)} \\
q_{r}^{M} & =\frac{g\left(k c_{n}-c_{r}\right)}{2 k(1-k)}
\end{aligned}
$$

Substituting them into the into $p_{n}^{M *}, p_{r}^{M *}$, and the profit of the manufacturer provides the equilibrium outcomes of Model M in Table 2.

\section{Appendix C. Proof of Proposition 1}

Based on the outcomes of in Table 2, we can obtain that $\frac{\partial q_{n}^{M}}{\partial g}=\frac{k c_{n}-c_{r}}{2 k-2}$ and $\frac{\partial q_{r}^{M}}{\partial g}=\frac{k c_{n}-c_{r}}{2 k-2 k^{2}}$. Based on Assumption 8, we can easily obtain that $\frac{\partial q_{M}^{M}}{\partial g}<0, \frac{\partial q_{r}^{M}}{\partial g}>0$-that is, as revealed in Proposition 1, as the green consumerism increases, the optimal quantities of new (remanufactured) products decrease (increase). 


\section{Appendix D. Derivation Optimal Outcomes for Model O}

Plugging (1) into the (3) and (4), we can rewrite them as follows:

$$
\begin{aligned}
\max _{q_{n}} \pi_{m}^{O} & =\left(1-q_{n}-k q_{r}-c_{n}\right) q_{n}+f q_{r} \\
\max _{q_{n}} \pi_{r}^{O} & =\left(k\left(1-q_{n}-k q_{r}\right)-\frac{k(1-k) q_{r}}{g}-f-c_{r}\right) q_{r}
\end{aligned}
$$

Based on the above equation, we can obtain its first-order condition as follows:

$$
\begin{aligned}
& \partial \pi_{m}^{O} / \partial q_{n}=1-2 q_{n}-k q_{r}-c_{n} \\
& \partial \pi_{r}^{O} / \partial q_{r}=-2 k^{2} q_{r}-2 q_{r} \frac{k}{g}+2 q_{r} \frac{k^{2}}{g}+k-k q_{n}-f-c_{r}
\end{aligned}
$$

Solving the above equations gives the following equilibrium quantities:

$$
\begin{aligned}
& q_{n}^{O}=\frac{k g+2-2 k+f g+c_{r} g-2 k g c_{n}-2 c_{n}+2 k c_{n}}{3 k g+4-4 k} \\
& q_{r}^{O}=\frac{g\left(k c_{n}+k-2 f-2 c_{r}\right)}{k(3 k g+4-4 k)}
\end{aligned}
$$

Substituting them into the into (3), we can obtain its first-order condition as follows:

$$
\partial \pi_{m}^{O} / \partial w_{r}=\frac{\left(5 k^{2} g+8 k-8 k^{2}-10 k f g-4 k c_{r} g-k^{2} g c_{n}-16 f+16 f k-8 c_{r}+8 c_{r} k\right) g}{(3 k g+4-4 k)^{2} k}
$$

Solving the above equation gives the optimal patent license fee as follows:

$$
f=\frac{5 k^{2} g+8 k-8 k^{2}-4 k c_{r} g-k^{2} g c_{n}-8 c_{r}+8 k c_{r}}{2(5 k g+8-8 k)}
$$

Substituting it into the into $q_{n}^{O *}, q_{n}^{O *}, p_{n}^{O *}, p_{r}^{O *}$, and the profit of the both parties provides the equilibrium outcomes of Model $\mathrm{O}$ in Table 2.

\section{Appendix E. Proof of Proposition 2}

Based on the outcomes of in Table 2, we can obtain that $\frac{\partial q_{n}^{O}}{\partial g}=\frac{8(-1+k)\left(k c_{n}-c_{r}\right)}{(5 k g+8-8 k)^{2}}$ and $\frac{\partial q_{r}^{O}}{\partial g}=\frac{16(1-k)\left(k c_{n}-c_{r}\right)}{k(5 k g+8-8 k)^{2}}$. Based on Assumption 8, we can easily obtain that $\frac{\partial q_{n}^{O}}{\partial g}<0$, $\frac{\partial q_{r}^{O}}{\partial g}>0$-that is, as revealed in Proposition 2, as the green consumerism increases, the optimal quantities of new (remanufactured) products decrease (increase).

\section{Appendix F. Proof of Proposition 3}

To prove $q_{r}^{M}>q_{r}^{O}$, we have to show that: $q_{r}^{M}-q_{r}^{O}=\frac{g\left(k c_{n}-c_{r}\right)}{2 k(1-k)}-\frac{2 g\left(k c_{n}-c_{r}\right)}{k(5 k g+8-8 k)}$. After simplification, we have that $\frac{\left(k c_{n}-c_{r}\right) g(5 k g+4-4 k)}{2 k(1-k)(5 k g+8-8 k)}$. Based on Assumption 8 , we can easily obtain that $q_{r}^{M}-q_{r}^{O}>0$. This means that the optimal quantities of remanufactured products in Model $\mathrm{M}$ are higher than those in Model O, i.e., $q_{r}^{M}>q_{r}^{O}$.

Furthermore, $\partial\left(q_{r}^{M}-q_{r}^{O}\right) / \partial g=\frac{\left(k c_{n}-c_{r}\right)\left(25 k^{2} g^{2}+80 k g-80 k^{2} g+32-64 k+32 k^{2}\right)}{2 k(1-k)(5 k g+8-8 k)^{2}}$. Based on Assumption 8, we can easily obtain that $\partial\left(q_{r}^{M}-q_{r}^{O}\right) / \partial g>0$.

\section{Appendix G. Proof of Proposition 4}

To prove $q_{n}^{M}<q_{n}^{O}$, we have to show that: $q_{n}^{M}-q_{n}^{O}=\frac{1-k+g c_{r}-k g c_{n}-c_{n}+k c_{n}}{2(1-k)}-\frac{2 g\left(k c_{n}-c_{r}\right)}{k(5 k g+8-8 k)}$. After simplification, we have that $\frac{g\left(k c_{n}-c_{r}\right)(5 k g-6 k+6)}{2(-1+k)(5 k g+8-8 k)}$. Based on Assumption 8, we can easily obtain that $q_{n}^{M}-q_{n}^{O}<0$. This means that the optimal quantities of new products in Model $\mathrm{M}$ are lower than those in Model O, i.e., $q_{n}^{M}<q_{n}^{O}$. 
Furthermore, $\partial\left(q_{n}^{M}-q_{n}^{O}\right) / \partial g=\frac{\left(k c_{n}-c_{r}\right)(5 k g+12-12 k)(5 k g+4-4 k)}{2(k-1)(5 k g+8-8 k)^{2}}$. Based on Assumption 8, we can easily obtain that $\partial\left(q_{n}^{M}-q_{n}^{O}\right) / \partial g>0$.

\section{Appendix H. Proof of Proposition 5}

To prove $\pi_{m}^{M}>\pi_{m}^{O}$, we have to show that: $\pi_{m}^{M}-\pi_{m}^{O}=\frac{g\left(-c_{r}+k c_{n}\right)^{2}(5 k g+4-4 k)}{4 k(1-k)(5 k g+8-8 k)}$. Based on Assumption 8, we can easily obtain that $\pi_{m}^{M}>\pi_{m}^{O}$. This means that the manufacturer's profitability in Model $\mathrm{M}$ is higher than that in Model O, i.e., $\pi_{m}^{M}>\pi_{m}^{O}$.

Furthermore, $\partial\left(\pi_{m}^{M}-\pi_{m}^{O}\right) / \partial g=\frac{\left(k c_{n}-c_{r}\right)^{2}\left(25 k^{2} g^{2}-80 k^{2} g+80 k g-64 k+32+32 k^{2}\right)}{4(1-k)(5 k g+8-8 k)^{2}}$. Based on Assumption 8, we can easily obtain that $\partial\left(\pi_{m}^{M}-\pi_{m}^{O}\right) / \partial g>0$.

\section{Appendix I. Proof of Proposition 6}

Solving $E^{M}-E^{O}=\frac{g\left(-c_{r}+k c_{n}\right)\left(-6 i_{n} k^{2}+5 i_{n} k^{2} g-5 i_{r} g k+6 i_{n} k+4 i_{r} k-4 i_{r}\right)}{2 k(k-1)(5 k g+8-8 k)}$, we can easily obtain that there is a threshold value of $g_{0}=\frac{2\left(3 i_{n} k^{2}-3 i_{n} k-2 i_{r} k+2 i_{r}\right)}{5 k\left(i_{n} k-i_{r}\right)}$, below which the total environmental impacts in Model $\mathrm{M}$ are lower than those in Model O-that is, $E^{M}<E^{O}$. Otherwise, $E^{M}>E^{O}$ is true.

\section{Appendix J. Proof of Proposition 7}

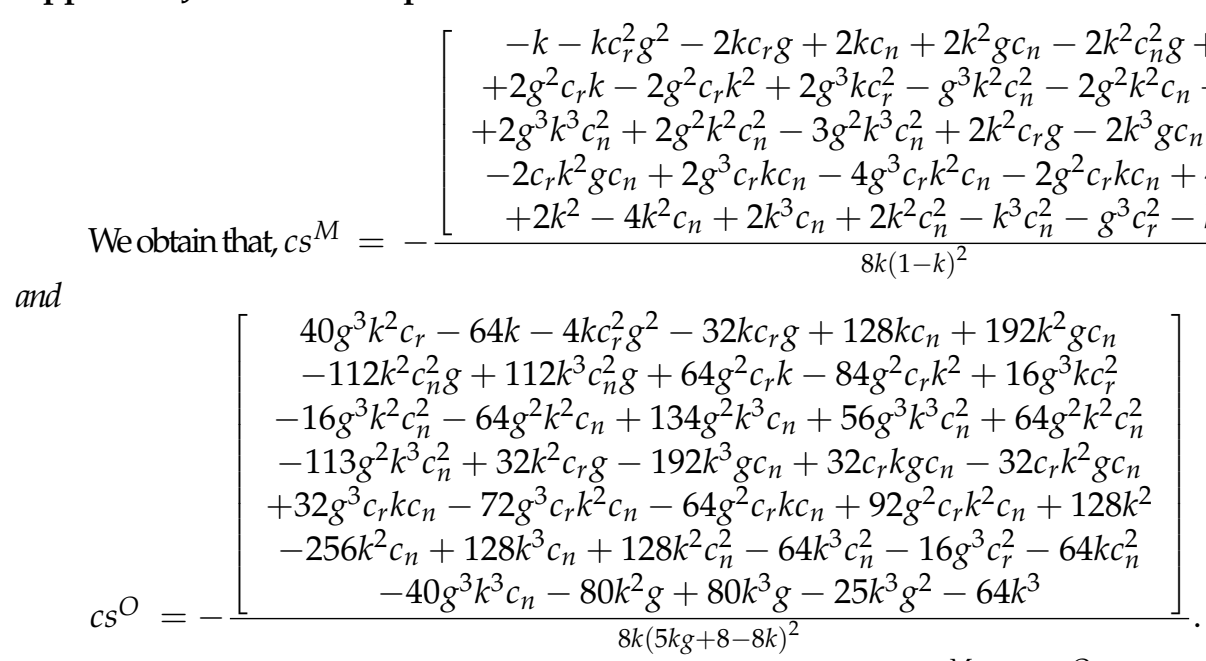

Based on Assumption 8, we can easily obtain that $c s^{M}<c s^{O}$. That means the consumer surplus in Model $\mathrm{M}$ is lower than that in Model $\mathrm{O}$.

\section{References}

1. Gable, F.J.; Gentile, J.H.; Aubrey, G.D. Global Climatic Issues in the Coastal Wider Caribbean Region. Environ. Conserv. 1990, 17, 51-60. [CrossRef]

2. Gina, T.; Michele, D.; Shixin, L. Special Issue “Advances in Green Manufacturing and Optimization”. 2021. Available online: https: //www.mdpi.com/journal/processes/special_issues/Advances_Green_Manufacturing_Optimization (accessed on 22 October 2021).

3. Global Times. EU Aims to Cut Carbon Dioxide Emissions by 40 Pct by 2030. 2016. Available online: https://www.globaltimes. $\mathrm{cn} /$ content/1021277.shtml (accessed on 2 October 2021).

4. Xinhua. Carbon Neutrality, China's Realizable Commitment to the World. 2021. Available online: http://www.china.org.cn/ opinion/2021-02/02/content_77180870.htm (accessed on 2 October 2021).

5. Kaya, O. Incentive and production decisions for remanufacturing operations. Eur. J. Oper. Res. 2010, 201, 442-453. [CrossRef]

6. Dowlatshahi, S. Developing a Theory of Reverse Logistics. Interfaces 2000, 30, 143-155. [CrossRef]

7. Giutini, R.; Gaudette, K. Remanufacturing: The next great opportunity for boosting US productivity. Bus. Horiz. 2003, 46, 41-48. [CrossRef]

8. Remanufacturing Industries Council (RIC). The Impacts of Remanufacturing. 2021. Available online: http://www.remancouncil.org/ (accessed on 2 October 2021).

9. Gleim, M.R.; Smith, J.S.; Andrews, D.; Cronin, J.J., Jr. Against the Green: A Multi-method Examination of the Barriers to Green Consumption. J. Retail. 2013, 89, 44-61. [CrossRef] 
10. Moisander, J.; Pesonen, S. Narratives of sustainable ways of living: Constructing the self and the other as a green consumer. Manag. Decis. 2012, 40, 329-342. [CrossRef]

11. Eurobarometer. The Attitudes of European Citizens towards Environment. 2005. Available online: http://www.europafacile.net/ Formulari/POLITICHE/Ambiente/report_ebenv_2005_04_22_en.pdf (accessed on 2 October 2021).

12. Takungpao.com. 2016 China Green Consumer Report (In Chinese). 2016. Available online: http://news.takungpao.com/ mainland/focus/2016-08/3353369_print.html (accessed on 2 October 2021).

13. Ho, J.W.; Huang, Y.S.; Hsu, C.L. Pricing under internal and external competition for remanufacturing firms with green consumers. J. Clean. Prod. 2018, 202, 150-159. [CrossRef]

14. Tully, S.M.; Winer, R.S. The Role of the Beneficiary in Willingness to Pay for Socially Responsible Products: A Meta-analysis. J. Retail. 2014, 90, 255-274. [CrossRef]

15. Guide, V.; Li, J. The Potential for Cannibalization of New Products Sales by Remanufactured Products. Decis. Sci. 2010, 41, 547-572. [CrossRef]

16. Hauser, W.M.; Lund, R.T. The Remanufacturing Industry: Anatomy of a Giant: A View of Remanufacturing in America Based on a Comprehensive Survey across the Industry. Dept. of Manufacturing Engineering. 2008. Available online: www.bu.edu/reman (accessed on 18 October 2017).

17. Hong, Z.; Zhang, Y.; Yu, Y.; Chu, C. Dynamic pricing for remanufacturing within socially environmental incentives. Int. J. Prod. Res. 2019, 3, 1-22. [CrossRef]

18. Wen, D.; Xiao, T.; Dastani, M. Channel choice for an independent remanufacturer considering environmentally responsible consumers. Int. J. Prod. Econ. 2020, 232, 107941. [CrossRef]

19. Wen, Z.A.; Yi, H.B. Optimal policies for new and green remanufactured short-life-cycle products considering consumer behavior. J. Clean. Prod. 2019, 214, 483-505. [CrossRef]

20. Ferguson, M. Strategic Issues in Closed-Loop Supply Chains with Remanufacturing. Closed 2009, 12, 1-14. [CrossRef]

21. Lei, Y.; Wang, G.; Ke, C. Remanufacturing and promotion in dual-channel supply chains under cap-and-trade regulation. J. Clean. Prod. 2018, 204, 939-957. [CrossRef]

22. Zou, Z.-B.; Wang, J.J.; Deng, G.S.; Chen, H. Third-party remanufacturing mode selection: Outsourcing or authorization? Transp. Res. Part E Logist. Transp. Rev. 2016, 87, 1-19. [CrossRef]

23. Yang, L.; Hu, Y.; Huang, L. Collecting mode selection in a remanufacturing supply chain under cap-and-trade regulation. Eur. J. Oper. Res. 2020, 287. [CrossRef]

24. Kushwaha, S.; Ghosh, A.; Rao, A.K. Collection activity channels selection in a reverse supply chain under a carbon cap-and-trade regulation. J. Clean. Prod. 2020, 260, 121034. [CrossRef]

25. Webster, S.; Mitra, S. Competitive strategy in remanufacturing and the impact of take-back laws. J. Oper. Manag. 2007, 25, 1123-1140. [CrossRef]

26. Hong, Z.; Chu, C.; Yu, Y. Dual-mode production planning for manufacturing with emission constraints. Eur. J. Oper. Res. 2016, 251, 96-106. [CrossRef]

27. Mitra, S.; Webster, S. Competition in remanufacturing and the effects of government subsidies. Int. J. Prod. Econ. 2008, 111, 287-298. [CrossRef]

28. Han, X.; Yang, Q.; Shang, J.; Pu, X. Optimal strategies for trade-old-for-remanufactured programs: Receptivity, durability, and subsidy. Int. J. Prod. Econ. 2017, 193, 602-616. [CrossRef]

29. Ji, J.; Zhang, Z.; Yang, L. Comparisons of initial carbon allowance allocation rules in an O2O retail supply chain with the cap-and-trade regulation. Int. J. Prod. Econ. 2017, 187, 68-84. [CrossRef]

30. Mahmoudi, R.; Morteza, R.-B. Sustainable supply chains under government intervention with a real-world casecase study: An evolutionary game theoretic approach. Comput. Ind. Eng. 2018, 116, 130-143. [CrossRef]

31. Wei, Y.; Yan, W.; Xiong, Y.; Xiong, Z.; Guo, N. Bricks vs. clicks: Which is better for marketing remanufactured products? Eur. J. Oper. Res. 2015, 242, 434-444. [CrossRef]

32. Agrawal, V.V.; Atasu, A.; Ittersum, K.v. Remanufacturing, Third-Party Competition, and Consumers' Perceived Value of New Products. Manag. Sci. 2015, 61, 60-72. [CrossRef]

33. Zhang, F.; Chen, H.; Xiong, Y.; Yan, W.; Liu, M. Managing collecting or remarketing channels: Different choice for cannibalisation in remanufacturing outsourcing. Int. J. Prod. Res. 2021, 59, 5944-5959. [CrossRef]

34. Zhou, Y.; Xiong, Y.; Jin, M. Less is more: Consumer education in a closed-loop supply chain with remanufacturing. Omega 2021, 101, 102259. [CrossRef]

35. Abbey, J.D.; Meloy, M.G.; Guide Jr, V.D.R.; Atalay, S. Remanufactured Products in Closed-Loop Supply Chains for Consumer Goods. Prod. Oper. Manag. 2015, 24, 488-503. [CrossRef]

36. Savaskan, R.C.; Bhattacharya, S.; Wassenhove, L.N.V. Closed-Loop Supply Chain Models with Product Remanufacturing. Manag. Sci. 2004, 50, 239-252. [CrossRef]

37. Spengler, J.J. Vertical Integration and Antitrust Policy. J. Political Econ. 1950, 58, 347-352. [CrossRef]

38. Atasu, A.; Souza, G.V.C. How Does Product Recovery Affect Quality Choice? Prod. Oper. Manag. 2013, 22, 991-1010. [CrossRef]

39. Agrawal, V.V.; Ferguson, M.; Toktay, L.B.; Thomas, V.M. Is Leasing Greener Than Selling? Manag. Sci. 2012, 58, 523-533. [CrossRef] 